\title{
Percutaneous Microwave Ablation of Hepatocellular Carcinoma
}

\author{
Ahmed M. El Sayed ${ }^{\mathrm{a}}$, Medhat M. Refaat ${ }^{\mathrm{b}}$, Mohamed M. El Shafei ${ }^{\mathrm{c}}$, Osama T. Galal ${ }^{\mathrm{b}}$
}

\begin{abstract}
a Department of radiology, Damanhur national medical institute, Egypt, ${ }^{\mathrm{b}}$ department interventional and diagnostic radiology, Faculty of Medicine, Banha University, Egypt, ${ }^{\mathrm{c}}$ department of interventional and diagnostic radiology, Faculty of medicine, Alexandria University, Egypt.
\end{abstract}

correspondence to: Ahmed M El Sayed (MSC), Department of radiology, Damanhur national medical institute, Egypt

email:

elwazanahmed@yahoo.com Received: 8 July 2019

Accepted: 15 October, 2019.

\begin{abstract}
Background: Hepatocellular carcinoma (HCC) is the commonest primary cancer of the liver. Incidence is increasing and HCC has risen to become the 5th commonest malignancy worldwide and the third leading cause of cancer related death. According to the BCLC staging system image-guided tumor ablation is recommended in patients with early stage HCC. Microwave ablation (MWA), is a thermal ablative technique that has recently emerged as a new therapeutic option. The aim of this study was to evaluate the use of microwave ablation in hepatocellular carcinoma treatment and to assess the outcome.
\end{abstract}

Methods: This study was carried out on 52 patients proved to have HCC who presented to Radiology Department in Alexandria University Hospitals. Microwave ablation was performed percutaneously under real-time ultrasound guidance using a GE LOGIQ 5 Pro US scanner (USA) with a 3.5-5 $\mathrm{MHz}$ probe, to completely destroy the tumor, as well as the surrounding $0.5-1.0 \mathrm{~cm}$ normal appearing liver tissue (safety margins). The patients were observed two hours before discharge. Contrast-enhanced triphasic CT imaging needed to be performed at 1 month after the ablation.

Results: All patients completed the procedure safely. The outcome, as determined by dynamic CT performed 1 month after percutaneous MWA, was achieved in 66 (97\%) of 68 lesions. The technical success rates for tumors smaller than $3 \mathrm{~cm}$ and those $3-5 \mathrm{~cm}$ were $97.2 \%$ (35 of 36 nodules) and $96.9 \%$ (31 of 32 nodules), respectively

Conclusion: Thermal ablation, including radiofrequency ablation (RFA) and microwave ablation (MWA), have been shown to be effective for treating HCC. Microwave ablation is a safe, effective and 
promising technique and a good replacement to surgical interference for patients who are not amenable to surgical therapy.

Keywords:Microwave ablation;

Hepatocellular carcinoma; Thermal ablation; percutaneous ablation

\section{1- Introduction:}

Hepatocellular carcinoma (HCC) is the commonest primary cancer of the liver. Incidence is increasing and $\mathrm{HCC}$ has risen to become the 5th commonest malignancy worldwide and the third leading cause of cancer related death, exceeded only by cancers of the lung and stomach (1). The estimated incidence of new cases is about 500 000-1 000000 per year, causing 600000 deaths globally per year (2 \& 3) Patients with cirrhosis are at the highest risk of developing HCC and should be monitored carefully to diagnose a possible tumor at an early-stage (4). Correct detection, classification and characterization of focal lesions are of paramount importance as they may significantly affect the choice of therapeutic approach in many cases (5).

According to the BCLC staging system image-guided tumor ablation is recommended in patients with early stage HCC (6). Image-guided percutaneous ablation is currently accepted as the best therapeutic choice for nonsurgical patients with early-stage disease (7).
For the treatment of $\mathrm{HCC}$, minimally invasive locoregional therapies include radiofrequency ablation (RFA), ethanol injection, microwave ablation, cryoablation, irreversible electroporation (IRE), and highintensity focused ultrasound (HIFU) ablation (8).The purpose of thermal ablative treatments is to destroy solid tumors by raising their temperature above a lethal threshold $\quad\left(60{ }^{\circ} \mathrm{C}\right.$ for instantaneous coagulative necrosis, $50{ }^{\circ} \mathrm{C}$ for prolonged exposure to heat) through direct energy deposition, which eventually turns into heat within a limited and controlled range of action (9).

RFA rapidly became the gold standard in ablation, especially in the treatment of small HCC nodules, at first flanking and eventually replacing percutaneous ethanol injection (PEI) treatments. However, RFA exhibits substantial performance limitations in the treatment of large lesions and/or tumors located near major heat sinks (9).

Consequently, the shape and size of the ablation zone may be unpredictable and the efficacy of RFA may be restricted as multiple sessions are necessary for complete tumour eradication (10).

MWA uses electromagnetic energy (up to 2 $\mathrm{cm}$ surrounding the antenna); in the absence of current flow, the electromagnetic field creates a rapid and homogeneous heating of 
tissue and subsequently coagulation necrosis. The best heating effect is achieved in tissues with a high content of water and the worst is observed in fat (11). The aim of this study is to evaluate the use of microwave ablation in hepatocellular carcinoma treatment and to assess the outcome.

\section{2- Patients and Methods}

From June 2017 to February 2019, a total of 90 patients with $\mathrm{HCC}$, deemed unsuitable for hepatic resection were referred to the interventional radiology department from the hepatic surgery department at Alexandria University Hospital. A total of 52 patients were recruited into this prospective study and treated with ultrasound-guided percutaneous MWA. The study was approved by the medical ethics committee of the hospital.

The 52 Patients included in our study had one of the following criteria:

- Single nodular HCC lesions of $5 \mathrm{~cm}$ or smaller.

- Less than five nodular HCC lesions with a maximum dimension of $5 \mathrm{~cm}$ or less in each nodule.

- Absence of portal vein thrombosis.

- Absence of extra-hepatic metastases.

- Elevated alpha feto-protein.

Exclusion criteria were liver decomposition, end stage kidney or critical heart disease, and obstructive jaundice either related or non related to the targeted lesion.

\section{2-2. Ablation procedure.}

Microwave ablation was performed percutaneously under real-time ultrasound guidance using a GE LOGIQ 5 Pro US scanner (USA) with a 3.5-5 $\mathrm{MHz}$ probe. The ablation procedure was performed under general anesthesia with propofol (Diprivan). MWA was performed using as HS AMICA microwave delivery system (HS Hospital service S.P.A Roma, Italy).

The aim of the treatment was to completely destroy the tumor, as well as the surrounding $0.5-1.0 \mathrm{~cm}$ normal appearing liver tissue (safety margins). A pre-incision of the skin is done and a 14-gauge $15 \mathrm{~cm}$ guide needle with a sheath was inserted and positioned at the designated place of the tumor under sonographic guidance, then the stylet of the guide needle was pulled out.

After the microwave electrode was introduced through the sheath of the guide needle, the sheath was withdrawn approximately 4-5 cm while keeping the electrode needle at its place to ensure that a portion of at least $4 \mathrm{~cm}$ from the tip of the electrode was exposed. Usually the tip of the electrode has to be placed at the bottom of the lesion about $0.5 \mathrm{~cm}$ inside the tumor margin. 
During each application of microwave energy, an expanding hyperechogenic area was produced which roughly judges the size of the ablation zone, i.e., necrotic zone. The necrosis length overcomes the tip of the electrode ahead by few $\mathrm{mm}(2-6 \mathrm{~mm})$ depending on power and time of the treatment while the biggest increase occurs backwards and radially as the time goes over.

These changes are visible on sonographic images but diminished rapidly as soon as the microwave generator was switched "off" and completely disappeared within $8 \mathrm{~h}$. To minimize tumor seeding, the needle track was routinely ablated while withdrawing the antenna at about $2 \mathrm{~cm} / \mathrm{s}$ (track ablation) The power has to be set at $40 \mathrm{~W}$, After the MWA procedure, the punctured site is covered with a sterile dressing under pressure.

The patients were observed two hours before discharge. Contrast-enhanced triphasic CT imaging needed to be performed at 1 month after the ablation. If irregular peripheral enhancement occurred, which represents residual unablated tumor, this sign indicates incomplete ablation. If complete ablation is achieved, then routine triphasic CT and serum tumor marker are repeated every 3 months.

\section{3-Data Management and Statistical analysis:}

Data were collected, coded, revised and entered to the Statistical Package for Social
Science (IBM SPSS) version 20 (Chicago, Ill, USA). The data were presented as number and percentages for the qualitative data, mean, standard deviations and ranges for the quantitative data with parametric distribution and median with inter quartile range (IQR) for the quantitative data with non parametric distribution.

Chi-square test was used in the comparison between two groups with qualitative data and Fisher exact test was used instead of the Chisquare test when the expected count in any cell found less than 5 .

-Independent t-test was used in the comparison between two groups with quantitative data and parametric distribution and Mann-Whitney test was used in the comparison between two groups with quantitative data and non parametric distribution.

- The confidence interval was set to $95 \%$ and the margin of error accepted was set to $5 \%$. So, the p-value was considered significant as the following:

- $\mathrm{P}>0.05$ : Non significant (NS)

$-\mathrm{P}<0.05$ : Significant $(\mathrm{S})$

- $\mathrm{P}<0.01$ : Highly significant (HS) 


\section{4- Results:}

According to the patient inclusion and exclusion criteria, a total of 52 patients were included (43 men and 9 women) with a mean age of $58.5+4.47$ years (range: $48-71$ years) with significant male predominance $(82.7 \%)$ (Table 1).

All the patients (100\%) had established liver cirrhosis (table 1). 51 patients $(98.1 \%)$ were infected with hepatitis C virus (HCV), while the other one $(1.9 \%)$ had hepatitis B virus (HBV) infection (table 1).

All patients were staged according to ChildPugh classification as $41(78.8 \%)$ of them as stage A while the other $11(21.2 \%)$ patients were stage B. (table 1).

Table (1). Demographic data, cirrhosis, hepatitis and Child-Pugh class

\begin{tabular}{llll}
\hline Gender & Female & 9 & $17.3 \%$ \\
& Male & 43 & $82.7 \%$ \\
Age & Mean \pm SD & $58.54 \pm 4.47$ \\
& Range & $48-71$ & \\
Cirrhosis & Present & 52 & $100.0 \%$ \\
Cirrhosis & Present & 52 & $100.0 \%$ \\
Hepatitis & HBV & 1 & $1.9 \%$ \\
Child-Pugh & HCV & 51 & $98.1 \%$ \\
class & Class A & 41 & $78.9 \%$ \\
& Class B & 11 & $21.2 \%$ \\
\hline
\end{tabular}

Among all the patients, 36 (69.2\%) patients had single lesion, 16 (30.8\%) had two lesions (table 2).
Ultrasound findings of the patients before the procedure showed that $43(63.2 \%)$ hepatic focal lesions were detected in the right lobe and $25(36.8 \%)$ focal lesions were detected in the left lobe (table 2).

The mean size of the focal lesions was $3.05+$ $0.47 \mathrm{~cm}$, with a range of $2.2-4.5 \mathrm{~cm}$. The PV was patent in all studied patients without ascites. Percutaneous US guided Microwave was utilized to ablate these 68 focal lesions (table 2).

Table (2). Lesion number, size and distribution.

\begin{tabular}{llll}
\hline & & No & $\%$ \\
\hline \multirow{2}{*}{ Number of lesions } & Single & 36 & $69.2 \%$ \\
& Two & 16 & $30.8 \%$ \\
Location & LT & 25 & $36.8 \%$ \\
& RT & 43 & $63.2 \%$ \\
tumor size $/ \mathbf{c m}$ & Mean \pm SD & $3.05 \pm 0.47$ \\
& Range & 2.2 & -4.5 \\
\hline
\end{tabular}

The mean procedure time for MWA was $12.1+1.64$ min ranging from $8-15 \mathrm{~min}$., and the mean power used was $66.2+1.6 \mathrm{~W}$ during the MWA.

All patients completed the procedure safely. The outcome, as determined by dynamic CT performed 1 month after percutaneous MWA, was achieved in 66 (97\%) of 68 lesions (table 3). 
Table (3): Study results.

\begin{tabular}{llll}
\hline & & No & $\%$ \\
\hline \multirow{2}{*}{ Result } & Complete ablation & 66 & $97.1 \%$ \\
& Incomplete ablation & 2 & $2.9 \%$ \\
\hline
\end{tabular}

The technical success rates for tumors smaller than $3 \mathrm{~cm}$ and those $3-5 \mathrm{~cm}$ were $97.2 \%$ (35 of 36 nodules) and 96.9\% (31 of 32 nodules), respectively (table 4 ).

Table (4). Complete/ incomplete ablation regarding tumor size.

\begin{tabular}{|c|c|c|c|c|c|c|c|}
\hline & & \multicolumn{4}{|c|}{ Tumor size /cm (1) } & \multirow{2}{*}{$\begin{array}{l}\text { Chi } \\
\text { test }\end{array}$} & \multirow[t]{2}{*}{ square } \\
\hline & & \multicolumn{2}{|c|}{$<3 \mathrm{~cm}$} & \multicolumn{2}{|c|}{$3-5 \mathrm{~cm}$} & & \\
\hline & & No & $\%$ & No & $\%$ & $\mathrm{X} 2$ & $\begin{array}{l}\mathrm{P} \\
\text { value }\end{array}$ \\
\hline \multirow{2}{*}{$\underset{\mathscr{E}}{\stackrel{\varpi}{\Xi}}$} & $\begin{array}{l}\text { Complete } \\
\text { ablation }\end{array}$ & 35 & 97.2 & 31 & 96.9 & \multirow{2}{*}{0.007} & \multirow{2}{*}{0.933} \\
\hline & $\begin{array}{l}\text { Incomplete } \\
\text { ablation }\end{array}$ & 1 & 2.8 & 1 & 3.1 & & \\
\hline
\end{tabular}

The two incompletely ablated tumors were subjected to a second session of MWA and technical success was achieved in both. Follow-up for all cases extended for 6 months including the first follow-up after one month, three and six months following MWA. There was no change in the ChildPugh score before and one month after MWA. No statistically significant difference was found between the Child-Pugh score and the response to MWA. During this period, none of the patients died, no local recurrence was detected. Alpha-fetoprotein ( $\alpha-\mathrm{FP})$ was measured for all patients preoperatively, mean $\alpha$-FP was $342.62 \pm 276.29$ (Table 5).

Table (5): AFP before and after MWA.

\begin{tabular}{lllll}
\hline & Min & Max & Mean & SD \\
\hline $\begin{array}{l}\text { AFP before } \\
(\mathbf{n g} / \mathbf{m l})\end{array}$ & 82 & 1387 & 342.62 & 276.29 \\
$\begin{array}{l}\text { AFP after } \\
(\mathbf{n g} / \mathbf{m l})\end{array}$ & 5 & 240 & 36.96 & 46.80 \\
\hline
\end{tabular}

There was significant decline in the AFP level one month after ablation compared with that before the procedure $(36.96 \mathrm{ng} / \mathrm{mL}+$ 46.8, $\mathrm{P}<0.001)$ (Table 6).

Table (6): AFP before and after MWA.

\begin{tabular}{lcccc}
\hline & & \multicolumn{3}{c}{ Parried t test } \\
& Mean & SD & & P \\
& & & $\mathrm{T}$ & value \\
\hline $\begin{array}{l}\text { AFP before } \\
\text { (ng /ml) }\end{array}$ & 342.62 & 276.29 & & \\
$\begin{array}{l}\text { AFP after } \\
(\mathbf{n g} / \mathbf{m l})\end{array}$ & 36.96 & 46.80 & & \\
\hline
\end{tabular}

Distant tumor progression in the liver (de novo lesions) developed in 3 (5.7\%) patients, were recorded six months after the MWA (table7).No distant metastasis (extrahepatic) was recorded up till 6 moth follow up (Table 7). No major complication occurred related to the ablation procedure (Table 7). Minor complications including upper quadrant pain 37/52 (71.1\%) and low grade fever $\leq 38^{\circ} \mathrm{C} \quad 4 / 52 \quad(7.6 \%)$, was relieved with the oral administration of 
analgesics (Table 7). 2 patients developed non symptomatic mild pleural effusion that needed no treatment (Table 7).No other clinically relevant complications were observed.

Table (7) study results regarding local recurrence, complications and metastasis

\begin{tabular}{|c|c|c|c|}
\hline & & No & $\%$ \\
\hline Local recurrence & $\begin{array}{l}\text { No local } \\
\text { recurrence }\end{array}$ & - & - \\
\hline \multirow[t]{2}{*}{ Major complications } & No & - & - \\
\hline & Fever & 5 & $\begin{array}{l}9.6 \\
\%\end{array}$ \\
\hline \multirow[t]{2}{*}{ Minor complications } & Pain & 17 & $\begin{array}{l}32 . \\
7 \%\end{array}$ \\
\hline & $\begin{array}{l}\text { Pleural } \\
\text { effusion }\end{array}$ & 2 & $\begin{array}{l}3.8 \\
\%\end{array}$ \\
\hline $\begin{array}{l}\text { Distant tumor } \\
\text { progression in the liver } \\
\text { (d novo lesions) }\end{array}$ & yes & 3 & $\begin{array}{l}5.7 \\
\%\end{array}$ \\
\hline Distant metastasis & No & - & - \\
\hline
\end{tabular}

\section{Case no. (1)}

Male patient 58 years old of child-pugh class A, presented with left lobe, segment $\mathrm{IVb}, \mathrm{HCC}$ measuring about $2.9 \mathrm{~cm}$ in diameter. A single session of MWA was done (figures from 1-5).

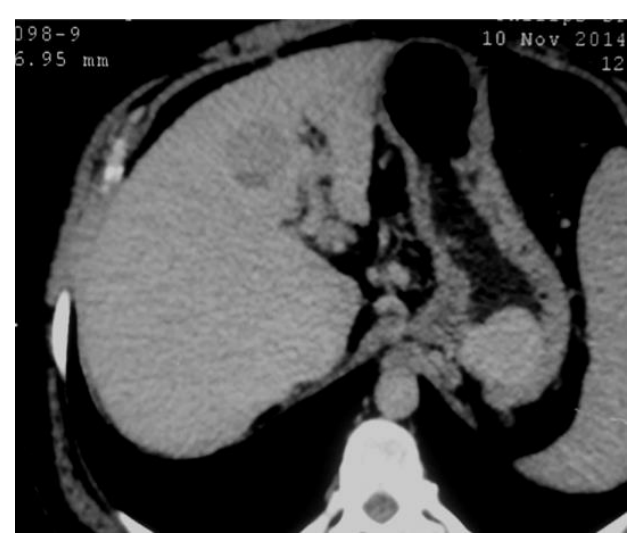

Fig. (1)

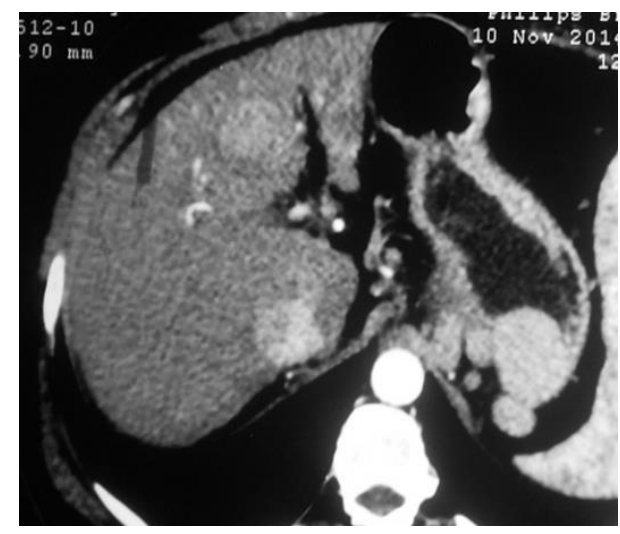

Fig. (2)

Fig.1 , 2: Triphasic CT scan shows enhancing left lobe focal lesion with washout in the delayed phase.

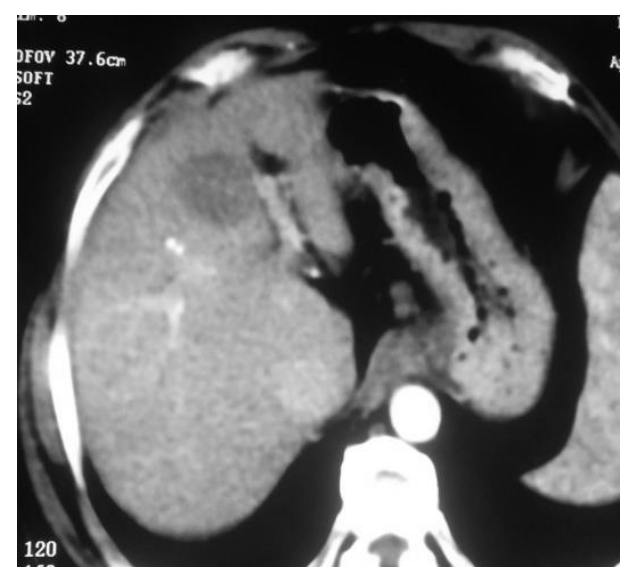

Fig. (3)

Fig. 3: Triphasic CT scan was done 1 month after ablation and the lesion was completely ablated. 


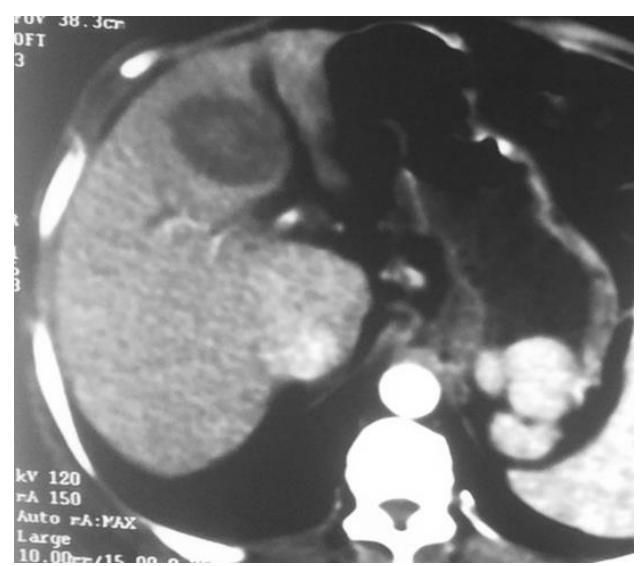

Fig. (4)

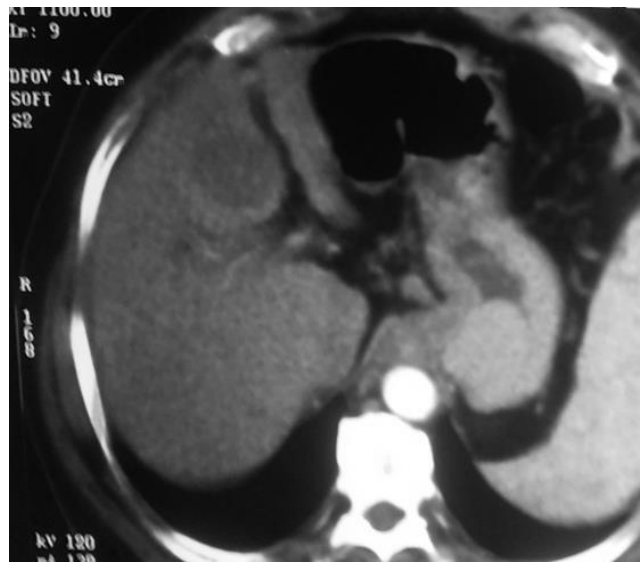

Fig. (5)

Fig. 4, 5: Follow up at 3 and 6 months with no evidence of either local or distant recurrence could be detected.

\section{Case no. (2)}

Male patient 63 years old of child-Pugh class A, presented with right lobe (V) HCC measuring about $3.0 \mathrm{~cm}$ in diameter. A single session of MWA was done (figures from 6-10).

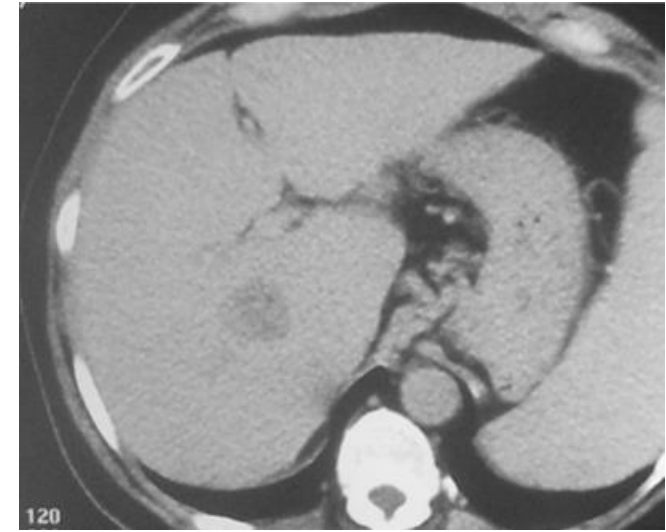

Fig. (6)

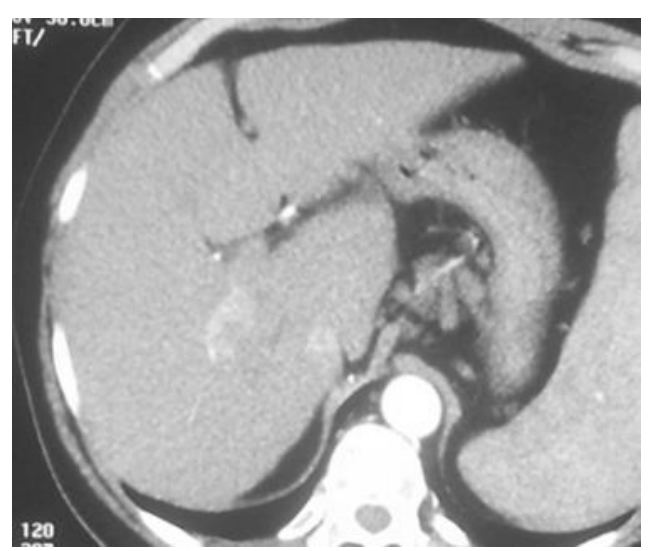

Fig. (7)

Fig. 6,7: Triphasic CT scan shows enhancing right lobe focal lesion with washout in the delayed phase.

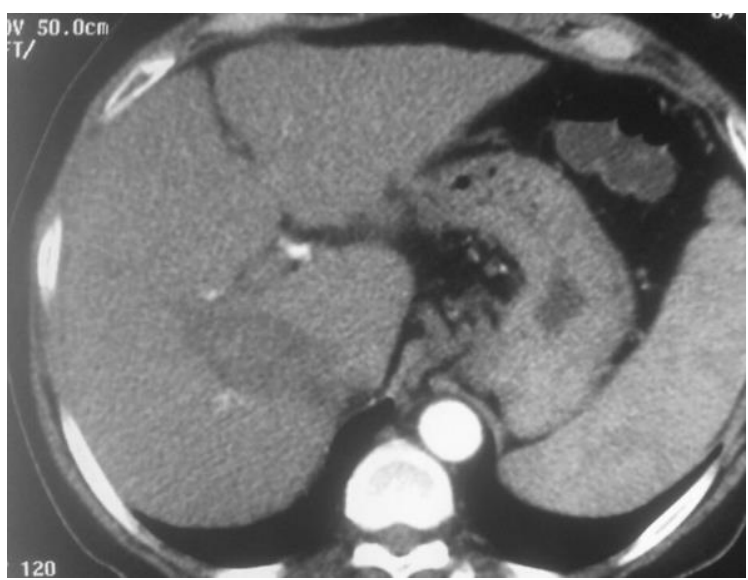

Fig (8): Triphasic CT scan was done 1 month after ablation and the lesion was completely ablated. 


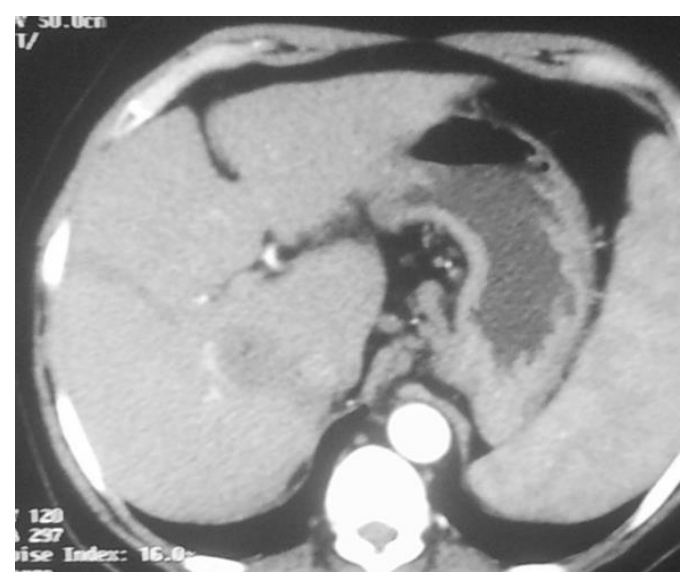

Fig.(9)

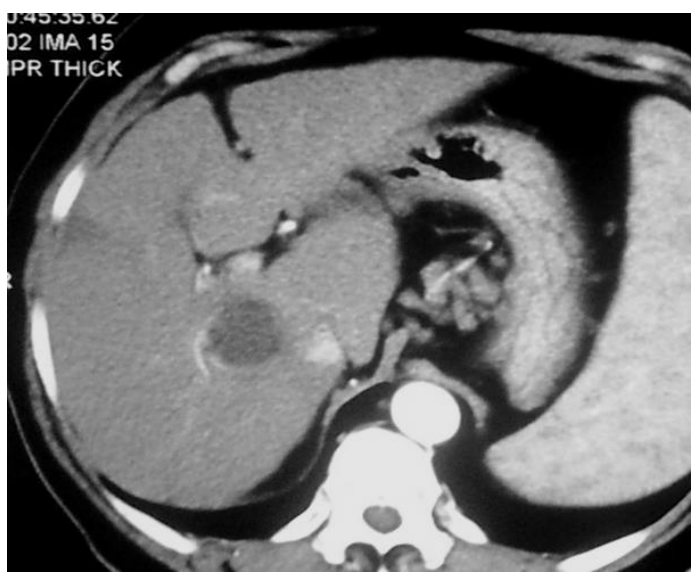

Fig.(10)

Fig.9,10: Follow up at 3 and 6 months with no evidence of either local or distant recurrence could be detected.

\section{Case no. (3)}

Male patient 49 years old of Child-Pugh class A, presented with left lobe, segment III, HCC measuring about $2.3 \mathrm{~cm}$ in diameter. Single session of MWA was done (figures from 11-15).

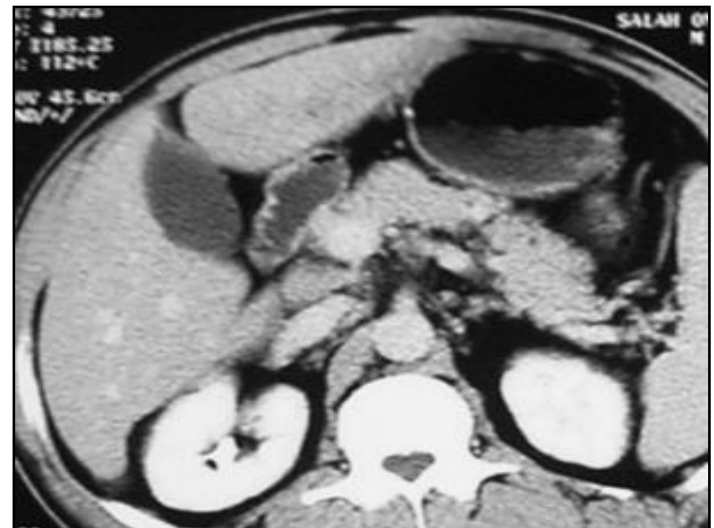

Fig. (11)

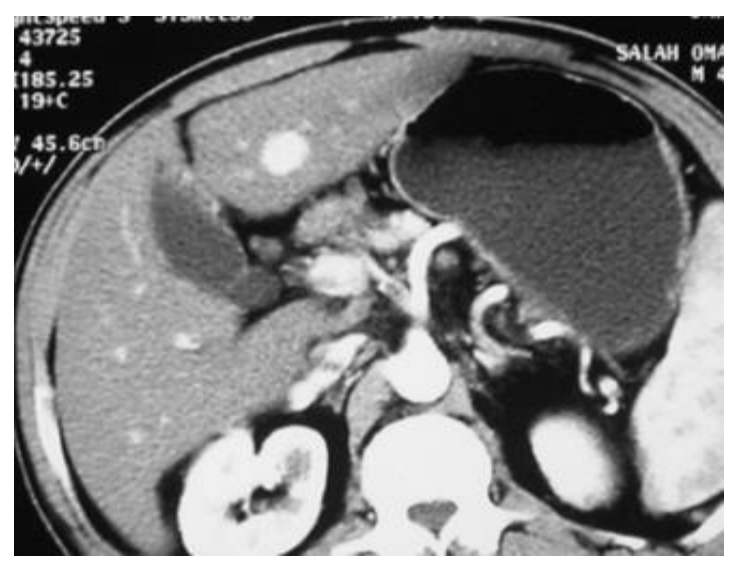

Fig.(12)

Fig. 11,12: Triphasic CT scan shows enhancing left lobe focal lesion with washout in the delayed phase

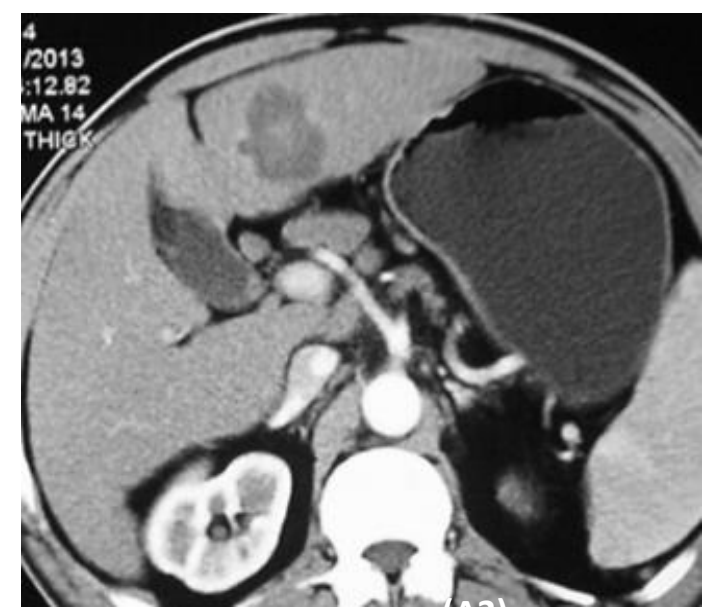

Fig. 13:Triphasic CT scan was done 1 month after ablation and the lesion was completely ablated 


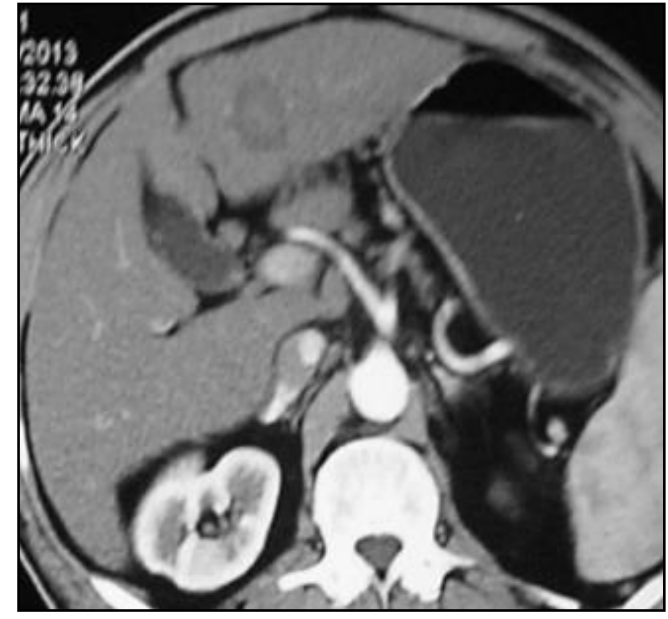

Fig. (14)

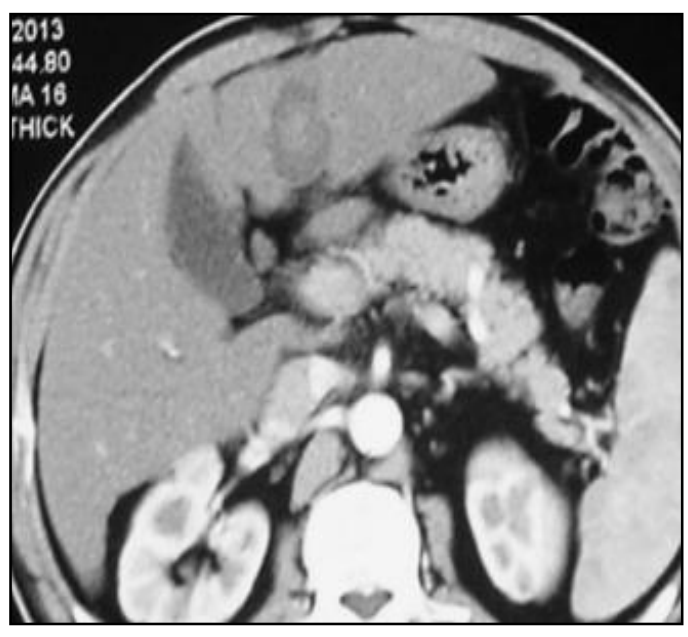

Fig. (15)

Fig. 14,15: Follow up at 3 and 6 months with no evidence of either local or distant recurrence could be detected

\section{5- Discussion:}

Treatment of HCC is a challenge that requires multi-disciplinary team to individualize therapy for each patient. Although orthotopic liver transplantation and primary resection are effective; underlying liver disease and shortage of liver donors are barriers against these modalities. Subsequently advances in loco regional therapies and targeted systemic therapy provide hope for patients in whom liver function and HCC morphology are obstacles against surgery. This is because loco regional therapies are minimally invasive and relatively safe, therefore can be repeated several times for $\mathrm{HCC}$ recurrence which exceeds $70 \%$ in 5 years (12).

Microwave ablation can be performed percutaneously, laparoscopically, thoracoscopically, or at laparotomy. Percutaneous treatment offers several advantages over other approaches (13).

The percutaneous approach is the least invasive, relatively expensive, can be performed on outpatient basis, and can be repeated to treat recurrent tumor, laparoscopic and thoraco-scopic approaches may be employed to ablate tumors at locations inaccessible by the percutaneous approach (13).

Our study was conducted on 52 patients by ultrasound guided percutaneous approach which was well tolerated by all patients and post procedural hospital admission was not required.This is in agreement with Abdel Aziz et al. who recorded a small rate of minor complications and there were no major complications or death occurred (14).

A large multicentric Italian study that included 14 centers that performed microwave ablations for 736 patients with 1,037 lesions finally confirmed the safety of 
microwave procedures with low rate of major complications (15)

The mean age of the patients in our study was $58.54 \pm 4.47$ years. Similar mean age group was studied by Soliman et al. (16). Older mean of age was documented to cases studied by Pusceddu et al. being $69 \pm 10.4$ (46-85) (17).

In nearly all populations, there was a higher rate of liver cancer in men than women, with usual male to female ratios of $2: 1$ to $4: 1$ on average (18). Similarly, in our study a significant male predominance was $82.7 \%$, as was also reported by Liu et al. with a male predominance of $92.5 \%$ (19).

Majority of our patients were infected with HCV (98.1\%) while the rest were HBVpositive $(1.9 \%)$. The same finding was observed by Poggi et al. (20).

This was in contrast to Liu et al. who found that their patients were mainly infected with HBV (98.75\%), this can be explained by the different groups of the studied patients (19). Additionally, most patients were classified as Child-Pugh A (78.9\%), while the Child-Pagh B was represented in (21.1\%) and this is similar to that of Medhat et al. (21).

Regarding the preprocedural ultrasound findings of our patients, all had liver cirrhosis with no PV thrombosis or ascites as this were part of our inclusion criteria for appropriate selection of the cases. This is in agreement with other studies Liu et al. \& Bruix et al. (19 $\& 22)$.

The majority of focal lesions in this study were detected in the right lobe, which is agreed by Abdel Aziz et al. \& Medhat et al. (14 \& 21) and disagreed by Hetta et al. which stated that the focal lesions were evenly distributed within the right and left lobes (24). This was explained by the fact that the right lobe is much larger than the left (25)., however in many of our cases the left lobe was larger which is expected in cirrhotic liver.

Most patients had solitary (69.2\%) lesions while the rest of patients $30.8 \%$ had two focal lesions which is confirmed by Liu et al. \& Yin et al. $(19 \& 26)$.

The mean procedural time of MWA was 12.3 $+3.1 \mathrm{~min}$ and the mean power was $57.8+$ 18.2 W; however, these were different from those from other studies done by Liu et al. \& Poggi et al. which may be attributed to the use of different microwave machines $(19 \&$ 20).

In our study we achieved a good overall success rate of $97 \%$ of ablation of initial complete ablation of 66 out of the 68 focal lesions ablated. The complete ablation rates for tumors $<3 \mathrm{~cm}$ and those $3-5 \mathrm{~cm}$ were $97.2 \%$ (35 of 36 nodules) and $96.9 \%$ (31 of 
32 nodules), respectively this was statistically non-significant $(\mathrm{P}$ value $=0.93)$.

This is disagreed with Hetta et al who stated that MW ablation success was higher in lesions less than $3 \mathrm{~cm}$ (57/58 lesion 98.3\%) in comparison to lesions more than $3 \mathrm{~cm}$ $(37 / 40,92.5 \%)(24)$.

The two lesions with suspected residual activity were treated with additional MW ablation sessions and complete ablation rates was achieved in both. These results were comparable to those reported by Martin et al. who treated 100 patients with 270 hepatic tumors. Of these patients, all 17 patients with HCC lesions measuring 2-5.9 $\mathrm{cm}$ achieved complete ablation, with a complete ablation rate of $100 \%$ (27). Similar results were obtained in the study done by Liu et al. with respect to tumors measuring $3-5 \mathrm{~cm}$ (19).

It is also comparable to the results of Poggi et al. who noted a complete ablation was achieved in $100 \%, 90 \%$ and $69 \%$ of small ( $<3 \mathrm{~cm}$ in diameter), intermediate and large lesions, respectively (20). Our results also agreed by $X u$ et al. who reported initial complete ablation rates of $98.3 \%$ (28).

Our results were different from the results of Shibata et al. whose technical success rates for ablating 46 focal lesions less than $4 \mathrm{~cm}$ in 36 patients was $89 \%$ (29).
Additionally our present results were also different from those of Soliman et al. whose reported $84.7 \%$ and $92 \%$ success rate for HCC in difficult sites and in the control group respectively (16).

We found that there was a significant decrease in the serum AFP level $(\mathrm{P}=0.001)$, after one month of the MW treatment which may be explained by the successful ablation in most of the treated lesions, which agreed by Mulier et al. \& Liu et al. (10\& 19).

We found no local recurrence at a median of 6 month after MW treatment which is agreed by Soliman et al. (16). Poggi et al. recorded recurrence in $10.5 \%$ of patients with large lesions (20), and Liu et al. recorded a local recurrence rate of $40.9 \%$ in large-sized (5-8 cm) lesions (19).

Also we noticed that there were denovo lesions in 3 patients $(5.7 \%)$ while Liu et al. \& Poggi et al. found de novo lesions in $27.7 \%$ and $50 \%$ respectively at a median of 6 months after MWA treatment, this higher rates may be a result of larger HCC size (5-8 cm) in their studies (19\& 20).

In this study no MW ablation related major complications were recorded, this may be attributed to the proper selection of the cases (Child A predominance) and lesions by excluding the focal lesions at risky locations (e.g. exophytic abutting a bowel loop or near common bile duct), this was in agreement 
with Medhat et al \& DE-Chao et al. $(21$ \& 30).

While $X u$ et al. reported that two patients $(0.7 \%)$ experienced major complications included intestinal perforation $(n=1)$, which was treated with intestinal surgery, and persistent jaundice $(n=1)(28)$.

However, using MW ablation in risky sites, major complications reported were also low, as reported by Zhou et al., (tumor seedling $1 / 53(1.9 \%)$ (31), Li et al. (moderate to massive pleural effusion 3/96 (3.1\%) sub capsular lesions) (32) and Huang et al. reported one case of portal vein thrombosis $(0.7 \%)$ and two cases of tumor seedling (1.4\%) out of 139 perivascular lesions (33).

Peri-procedural pain and fever are considered symptoms of post-ablation syndrome, which may be the result of an inflammatory response to the necrotic tissue with cytokines production (34).

In the present study $22(42.3 \%)$ patients experienced mild degree of fever and or pain with none of them reported pain that impaired their daily life.

These results were lower than reported by $X u$ et al. where they reported that pain and fever were observed in $65.5 \%$ (197/301) of patients (28). Pain was experienced in 17 out of the 52 patients $(32.6 \%)$ while low grade fever was noticed in 5 patients (7.6\%). This results was disagreed by Hetta et al. who reported three patients $(3.1 \%)$ whose tumors were located in the liver dome had severe right upper quadrant pain \& 48 out of 72 (66.6\%) patients had a mild fever (24).

Two patients developed non symptomatic mild pleural effusion $(3.8 \%)$ which compares favorably with what reported by Soliman et al. who reported 3 cases with subcapsular lesions that developed pleural effusion out of 44 patients $(6.8 \%)(16)$.

The occurrence of post thermal ablation pleural effusion was said to be due to transient pleurisy related to thermal effect. The direct thermal damage of pleural membranes might cause increased pleural capillary filtration and interferes with parietal pleural fluid removal leading to pleural effusion formation (35).

Although survival rates are beyond objectives of this study, yet in our limited study period (6 months), the survival rate was $100 \%$. This compares favorably with study of $L u$ et al. where the 1 year survival rate for 36 patients was 96\%, (36) and that of Ding et al. 1 year survival rate for 85 patients was $98.7 \%$ (37).

\section{6- References:}

1. Gomaa AI, Khan SA, Toledano MB, Waked I, Taylor-Robinson SD. Hepatocellular carcinoma: Epidemiology, risk factors and pathogenesis. World J Gastroenterol 2008; 14(27): 4300-4308 
2. Parkin DM, Pisani P, Ferlay J. Estimates of the worldwide incidence of 25 major cancers in 1990. Int J Cancer 1999; 80: 827-841

3. Yeh CT, Chen TC, Chang ML, Hsu CW, Yeh TS, Lee WC et al. Identification of NV-F virus DNA in hepatocellular carcinoma. J Med Virol 2007; 79: 92-96

4. Lencioni R, Cioni D, Pina CD, Crocetti L. Hepatocellular carcinoma: new options for imageguided ablation J Hepatobiliary Pancreat Sci 2010; 17:399-403

5. Holzapfel k, Bruegel M, Eiber M, Ganter C, Schuster T, Heinrich P, et al. Characterization of small $(\leq 10 \mathrm{~mm})$ focal liver lesions: value of respiratory-triggered echoplanar diffusion-weighted MR imaging. Europian Journal of radiology 2010; $86:: 89-95$.

6. Lencioni R, Crocetti L. Local-Regional Treatment of Hepatocellular Carcinoma. Radiology 2012; 262: 4358.

7. Llovet JM, Di Bisceglie AM, Bruix J, Kramer BS, Lencioni R, Zhu AX, et al. Design and endpoints of clinical trials in hepatocellular carcinoma. J Natl Cancer Inst. 2008;100:698-711.

8. Kang TW, Rhim H. Recent Advances in Tumor Ablation for Hepatocellular Carcinoma, Liver Cancer 2015; 4:176-187.

9. Poggi G, Tosoratti N, Montagna B, Picchi C. Microwave ablation of hepatocellular carcinoma. World J of hepatol 2015: 7 (25) 2578-2589

10. Mulier S, Ni Y, Jamart J, Ruers T, Marchal G, Michel L. Local recurrence after hepatic radiofrequency coagulation: multivariate metaanalysis and review of contributing factors. Ann Surg 2005; 242: 158-171.

11. Brace CL. Radiofrequency and microwave ablation of the liver, lung, kidney, and bone: what are the differences? Curr Probl Diagn Radiol 2009; 38: 135143.
12. Rhim H, Lim HK, Choi D. Current status of radiofrequency ablation of hepatocellular carcinoma. World J Gastrointest Surg 2010; 2(4):128-36.

13. Teratani T, Yoshida H, Shiina S, Obi S, Sato $\mathrm{S}$, Tateishi R, et al. Radiofrequency ablation for hepatocellular carcinoma in so-called high-risk locations. Hepatology 2006; 43(5): 1101-1108.

14. Abdelaziz AO, Elbaz TM, Shousha HI, Mahmoud S, Ibrahim M, Abdel Maksoud A, et al. Survival and prognostic factors for hepatocellular carcinoma: an Egyptian multidisciplinary clinic experience. Asian Pac J Cancer Prev 2014; 15: 3915-20.

15. Livraghi T, Meloni F, Solbiati L, Zanus G. Collaborative Italian Group using AMICA system. Complications of microwave ablation for liver tumors: results of a multicenter study. Cardiovasc Intervent Radiol. 2012; 35:868-874.

16. Soliman FA, Abouelkhair MM, Hasab Allah SA, ElKady NM, Ezzat WM, Gabr HA, et al. Efficacy and Safety of Microwave Ablation (MWA) for Hepatocellular Carcinoma (HCC) in Difficult Anatomical Sites in Egyptian Patients with Liver Cirrhosis. Asian Pac J Cancer Prev, 20 (1), 295-301.

17. Pusceddu C, Melis L, Ballicu N, Sotgia B, Melis M, Sanna V, et al. Percutaneous Microwave Ablation Under CT Guidance for Hepatocellular Carcinoma: a Single Institutional Experience. J Gastrointest Canc. 2017; 9951-8

18. Buch SC, Kondraqunta V, Branch RA, Carr BL. Gender-based outcomes differences in unresectable hepatocellular carcinoma. Hepatol Int. 2009; 2(1): 95101.

19. Liu J, Ding J, Jing X, Wang Y, Wang F, Wang Y, et al. Comparison of two different thermal techniques for the treatment of hepatocellular carcinoma. Eur $\mathbf{J}$ Radiol 2013; 82: 1379-1384.

20. Poggi G, Montagna B, Di Cesare P, Riva G, Bernardo G, Mazzucco $M$, et al. Microwave ablation of hepatocellular carcinoma using a new 
percutaneous device: preliminary results. Anticancer Res 2013; 33: 1221-7.

21. Medhat E, Abdel Aziz A, Nabeel M, El Baz T, Zakaria Z, Shousha $\mathrm{H}$, et al. Value of microwave ablation in treatment of large lesions of hepatocellular carcinoma. Journal of Digestive Diseases 2015; 16; 456-463.

22. Bruix J, Sherman M, Llovet JM, Beaugrand M, Lencioniet R, Burroughsal AK. et al. Clinical management of hepatocellular carcinoma. Conclusions of the Barcelona-2000 EASL conference. European Association for the Study of the Liver. J Hepatol 2001; 35: 421-30.

23. Hetta O. M, Shebrya N. H., Amin SK. Ultrasoundguided microwave ablation of hepatocellular carcinoma: Initial institutional experience. The Egyptian Journal of Radiology and Nuclear Medicine 2011; 42: 343-349.

24. Portmann BC. Chapter 1. In: O’Grady JG, Lake JR, Howdle P, eds. Comprehensive Clinical Hepatology. London: Mosby, 2000; 11.

25. Yin XY, Xie XY, Lu MD, XU HX, XU ZF, Kuang $M$, et al. Percutaneous thermal ablation of medium and large hepatocellular carcinoma: long-term outcome and prognostic factors. Cancer 2009; 115: 1914-23.

26. Martin RC, Scoggins CR, McMasters KM. Safety and efficacy of microwave ablation of hepatic tumors: a prospective review of a 5-year experience. Ann Surg Oncol 2010;17: 171-8.

27. Xu Y, Shen Q, Wang N, Wu PP, Huang B, Kuang $\mathrm{M}$, et al. Microwave ablation is as effective as radiofrequency ablation for very-early-stage hepatocellular carcinoma. Chin J Cancer (2017) 36:14.

28. Shibata T, Iimuro Y, Yamamoto Y, Maetani Y, Ametani F, Ltoh K, et al. Small hepatocellular carcinoma: comparison of radiofrequency ablation and percutaneous microwave coagulation therapy. Radiology 2002; 223: 331-337.
29. DE-Chao J, Zhou Q, Han XW, Ya-Feng W, Gang W, Jian-Zhuang $\mathrm{R}$, et al. Microwave ablation treatment of liver cancer with a 2,450-M cooled-shaft antenna: pilot study on safety and efficacy. Asian Pac J Cancer Prev 2012; 13: 737-42.

30. Zhou P, Liang $\mathrm{P}$, Yu X, Wang X, Dong B. Percutaneous microwave ablation of liver cancer adjacent to the gastrointestinal tract. J Gastrointest Surg. 2009; 13: 318-24.

31. Li M, Yu X, Liang P, Liu F, Dong B, Zhou P. Percutaneous microwave ablation for liver cancer adjacent to the diaphragm. Int $\mathbf{J}$ Hyperthermia. 2012; 28: 218-26.

32. Hang S, Yu J, Liang P, Xu X, Cheng Z, Han Z, et al. Percutaneous microwave ablation for hepatocellular carcinoma adjacent to large vessels: a long-term follow-up. Eur ,kjl,. J Radiol. 2014; 83: 552-8.

33. Carrafiello G, Lagana D, Ianniello A, Dionigi G, Novario R, Recaldini C, et al. Post-radiofrequency ablation syndrome after percutaneous radiofrequency of abdominal tumours: one centre experience and review of published works. Australas Radiol. 2007; 51: 550-4.

34. Chao WC, Liu CY, Lin CC, Lin JC, Wang HY, Tsai $\mathrm{SJ}$, et al. Pleural effusion after percutaneous radiofrequency Ablation for hepatic malignancies. J Cancer Res Pract 2015; 2: 22-30.

35. Lu DS, Raman SS, Limanond P, Aziz D, Economou $\mathrm{J}$, Busuttil R, et al. Influence of large peritumoral vessels on outcome of radiofrequency ablation of liver tumors. J Vasc Interv Radiol 2003;14: 1267-1274.

36. Ding J, Jing X, Liu J, Wang Y, Wang F, Wang Y, et al. Complications of thermal ablation of hepatic tumours: comparison of radiofrequency and microwave ablative techniques. Clin Radiol. 2013; 68(6): 608-15. 
To cite this article: Ahmed M. El Sayed, Medhat M. Refaat, Mohamed M. El Shafei, Osama T. Galal. Percutaneous Microwave Ablation of Hepatocellular Carcinoma BMFJ, 2019; 36(3)127-142. DOI: 10.21608/bmfj.2020.14585.1015 